\title{
New Technologies and Processes Toward Sustainable Society ${ }^{\dagger}$
}

\author{
Lucia D'Accolti ${ }^{1,2 *}$, Daniela Caputo ${ }^{1}$, Michele Casiello ${ }^{1}$, Caterina Fusco ${ }^{2}$, Angelo Nacci ${ }^{1,2}$ \\ 1 Dipartimento di Chimica, Università degli Studi di Bari “A. Moro", Via Orabona 4, 70126 Bari, Italy; \\ daniela.caputo@uniba.it (D.C.), michele.casiello@uniba.it (M.C.), angelo.nacci@uniba.it (A.N.); \\ 2 CNR - Istituto di Chimica dei Composti Organometallici (ICCOM), Bari section, via Orabona 4, 70126 Bari, Italy \\ fusco@ba.iccom.cnr.it (C.F.); \\ * Correspondence: lucia.daccolti@uniba.it; \\ $\uparrow$ Presented at Materials Chemistry and Physics (Materials Chemistry 2020) - International e-Conference
}

Received: 16.09.2020; Revised: 20.09.2020; Accepted: 24.09.2020; Published: 27.09.2020

\begin{abstract}
With the depletion of fossil sources, research is currently intensively focused on exploiting renewable ones. Particular attention is paid to wastes and raw materials for producing biodiesel, lubricants, surfactants, polymers, solvents, and fine chemicals [1-2].

In this area, heterogeneous catalysis plays a prominent role, due to the remarkable advantages of robustness and recyclability. A huge number of new heterogeneous nanocatalysts have been applied to exploiting biomass and raw materials $[3,4]$.

Another sustainable approach flows chemistry, which has rapidly gained interest due to the advantages of automation, reproducibility, safety, and easy up-scale. Many applications to the synthesis of vegetable oil derivatives and waxes are reported $[5,6]$.
\end{abstract}

Keywords: green oxidation; circular economy; bio-plastics; flow chemistry; photocatalysis.

(c) 2020 by the authors. This article is an open-access article distributed under the terms and conditions of the Creative Commons Attribution (CC BY) license (https://creativecommons.org/licenses/by/4.0/).

\section{Funding}

This work is partially supported by funds from European Union -19 FESR "PON Ricerca e Innovazione 2014-2020. Progetto: 20 Energie per l'Ambiente TARANTO-Cod. ARS01 00637”.

\section{Acknowledgments}

Acknowledge the Chemistry Student: Vincenzo Pantone, Amelita Grazia Laurenza, Francesca Russo.

\section{Conflicts of Interest}

The authors declare no conflict of interest.

\section{Refernces}

1. Pantone, V.; Annese, C.; Fusco, C.; Fini, P.; Nacci, A.; Russo, A.; D’Accolti, L. One-Pot Conversion of Epoxidized Soybean Oil (ESO) into Soy-Based Polyurethanes by MoCl2O2 Catalysis. Molecules 2017, 22, https://doi.org/10.3390/molecules22020333. 
2. Pantone, V.; Laurenza, A.G.; Annese, C.; Comparelli, R.; Fracassi, F.; Fini, P.; Nacci, A.; Russo, A.; Fusco, C.; D'Accolti, L. Preparation and Characterization of Soybean Oil-Based Polyurethanes for Digital Doming Applications. Materials 2017, 10, https://doi.org/10.3390/ma10080848.

3. D'Accolti, L.; Annese, C.; Fusco, C. Continued Progress towards Efficient Functionalization of Natural and Non-natural Targets under Mild Conditions: Oxygenation by $\mathrm{C}-\mathrm{H}$ Bond Activation with Dioxirane. Chemistry - A European Journal 2019, 25, 12003-12017, https://doi.org/10.1002/chem.201901687.

4. Fusco, C.; Casiello, M.; Catucci, L.; Comparelli, R.; Cotugno, P.; Falcicchio, A.; Fracassi, F.; Margiotta, V.; Moliterni, A.; Petronella, F.; D’Accolti, L.; Nacci, A. TiO2@PEI-Grafted-MWCNTs Hybrids Nanocomposites Catalysts for CO2 Photoreduction. Materials 2018, 11, https://doi.org/10.3390/ma11020307.

5. Pantone, V.; Laurenza, A.G.; Annese, C.; Fracassi, F.; Fusco, C.; Nacci, A.; Russo, A.; D’Accolti, L. Methanolysis of epoxidized soybean oil in continuous flow conditions. Industrial Crops and Products 2017, 109, 1-7, https://doi.org/10.1016/j.indcrop.2017.08.001.

6. Caputo, D.; Casiello, M.; Laurenza, A.G.; Fracassi, F.; Fusco, C.; Nacci, A.; D’Accolti, L. Preparation of Biowax Esters in Continuous Flow Conditions. ACS Omega 2019, 4, 12286-12292, https://doi.org/10.1021/acsomega.9b00861. 